\title{
Estimation of the Level of Glycosylated Hemoglobin as a Predictor Factor to Bevacizumab Injection in Diabetic Macular Edema in a Sample of Iraqi Patients
}

\author{
Hasanain Hasan Attar ${ }^{1}$, Farooq Mohammed Abbas ${ }^{2}$, Haider Layikh ${ }^{1 * \mathbb{D}}$ \\ ${ }^{1}$ Department of Surgery, Al-Qadisiyah University College of Medicine, Al Diwaniyah, Iraq; ${ }^{2}$ Department of Surgery, Jaber Bin \\ Hayyan Medical University, Najaf, Iraq
}

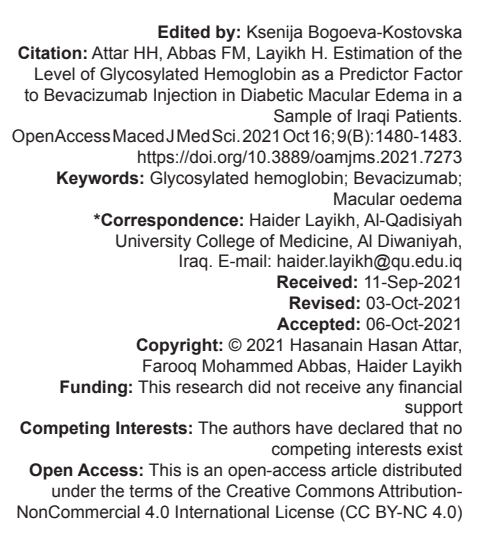

\section{Introduction}

Diabetic retinopathy, which considers as the leading cause of blindness in adults at the age of working is one of the inevitable sequels of diabetes [1]. The main reason of the decrease in vision in patients with diabetes is (diabetic macular edema), in which there will be an accumulation of fluid in the macula which lead to loss of central vision, consequently, will affect the patient ability for reading, recognition of face and driving [2]. The prevalence of (diabetic macular edema) is affected markedly by the duration of diabetes, where it is found to affect about $3 \%$ of those who are recently diagnosed with diabetes, on the other hand, its prevalence increase to affect up to $29 \%$ in those with diabetes for more than 20 years [3].

According to the result of the early treatment diabetic retinopathy study (ETDRS) group, the golden option for the treatment of diabetic macular edema) was laser photocoagulation either focal or grid. After 3 years of follow-up, there was deterioration in visual acuity (VA) with loss of 14 ETDRS letters in about $11 \%$ of eyes that receive laser treatment [4].

With the innovation of anti-vascular endothelial growth factor (VEGF) therapy, there was a revolutionary development in the management of (diabetic macular edema) [5]. Recently, anti-VEGF consider the standard care for the management of (diabetic macular edema).

Different clinical studies had approved the efficacy of VEGF inhibitors as treatment for diabetic macular edema including: RIDE/RISE [6], Diabetics retinopathy clinical research network protocol [7], Resolve [8], Restore [9], Vivid and Vista [10].

Researchers had found that anti-VEGF results in both anatomical and functional improvement 
in patients with diabetic macular edema [6], [11], [12]. The presence and progression of diabetic macular edema are affected by several local and systemic variables e.g. blood pressure level, presence of nephropathy, duration of diabetes, serum lipid, and glycosylated hemoglobin (HbA1C) level. Periodic assessment of $\mathrm{HbA} 1 \mathrm{C}$ can be used as a marker for the control of the glycemic status. The strict control of the blood sugar level had been proved to be a limiting factor for the development and progression of diabetic retinopathy [13].

Since diabetic retinopathy and diabetic macular edema consider as a microvascular complications of diabetes, it is important to assess the effect of metabolic control on the outcome with intravitreal antiVEGF injections. In a retrospective study, Ozturk et al. had reported a reduction in macular edema with antiVEGF therapy was negatively associated with $\mathrm{HbA} 1 \mathrm{C}$ level [14].

Matsuda et al. had found that "in patients with $\mathrm{HbA} 1 \mathrm{C}$ levels of more than seven there was less antiVEGF mediated improvement in (best-corrected VA) and central thickness of the macula than in patients with HbA1C of $<7$ " [15]. This study aims to evaluate the role of glycaemic control on eyes treated with intravitreal bevacizumab injections for patients complaining of macular edema.

\section{Materials and Methods}

This is prospective clinical study was done at Al-Diwanyia teaching hospital in the period from January 2020 till April 2021. Ninety-five patients (55 male: 40 female) were recruited in this study, all of them had diabetes type 2.

The age of the participants ranging from 42 to 70 years old and all the patients were asked to sign an informed consent. All research procedures followed the tenets of The Helsinki declaration. Complete ophthalmic examination was done for all the participants including best-corrected VA (converted to logmar), intraocular pressure checking (using Goldmann applanation tonometer), fundus evaluation, and central macular thickness measurement (by optical coherence tomography [OCT] spectral domain from optivue). Serum HbA1C was measured.

Any patient with prior vitreo-retinal surgery, laser photocoagulation either (focal, grid, or pan-retinal photocoagulation), anti-VEGF therapy, visual loss, or macular edema due to reasons apart from diabetes was excluded from this study. Based on baseline $\mathrm{HbA1C}$, participants were divided into two subgroups: those with $\mathrm{HbA} 1 \mathrm{C}$ equal or above 7 , another group with $\mathrm{HbA} 1 \mathrm{C}$ below 7 depending on (American diabetes association) statement on the generally accepted threshold of diabetes control treatment.

Patients were given $0.05 \mathrm{ml}(1.25 \mathrm{mg})$ of bevacizumab (Avastin) intravitreally for 3 successive months. The procedure was done in the theatre under aspetic circumstances, Bevacizumab (Avastin: Roche, Germany) was delivered to the vitreous cavity using a 30 gauge needle through pars plana approach, $3.5 \mathrm{~mm}$ behind the limbus in pseudo-phakic patients or $4 \mathrm{~mm}$ behind the limbus in the phakic patients.

Follow-up visits were at 4,8 , and 12 weeks post-injection. On each follow-up detailed examination was done including The best-corrected VA measurment, Intraocular pressure, both fundus examination, and OCT of the macula.

\section{Results}

We use the Social Science Statistical Package 16 edition and Microsoft Office Excel 2007 to analyze the data. The current study included 111 patients who had type 2 diabetes mellitus who were classified according to $\mathrm{HbA} 1 \mathrm{c}$ into two sub-groups, $\mathrm{HbA} 1 \mathrm{c}$ $\leq 7 \%(n=45)$ and $\mathrm{HbA} 1 \mathrm{c}>7 \%(\mathrm{n}=66)$. Comparison of mean age, frequency distribution according to gender, and mean $\mathrm{HbA} 1 \mathrm{c}$ between study groups is shown in Table 1. We found no significant difference in mean age and frequency distribution according to gender between study groups ( $p>0.05$ ), but, we found a highly significant difference in mean $\mathrm{HbA} 1 \mathrm{c} \%$ $(p<0.001)$.

Table 1: The comparison of mean age, frequency distribution according to gender and mean $\mathrm{HbA1c}$ between study groups

\begin{tabular}{llll}
\hline Characteristic & HbA1c $\leq 7 \%, \mathrm{n}=45$ & $\mathrm{HbA} 1 \mathrm{c}>7 \%, \mathrm{n}=66$ & $\mathrm{p}$-value \\
\hline $\begin{array}{l}\text { Age (years) } \\
\text { Mean } \pm \text { SD }\end{array}$ & $62.93 \pm 8.19$ & $59.27 \pm 7.98$ & 0.184 I \\
$\quad$ Range & $47-75$ & $38-69$ & $\mathrm{NS}$ \\
$\begin{array}{l}\text { Gender } \\
\quad \text { Male, } \mathrm{n}(\%)\end{array}$ & $36(80.0)$ & $33(50.0)$ & $0.065 \mathrm{C}$ \\
$\quad$ Female, $\mathrm{n}(\%)$ & $9(20.0)$ & $33(50.0)$ & $\mathrm{NS}$ \\
HbA1c & & $8.61 \pm 1.50$ & $<0.001$ I \\
$\quad$ Mean \pm SD & $6.59 \pm 0.31$ & $7.1-12$ & $\mathrm{NS}$ \\
$\quad$ Range & $5.9-7$ & & \\
\hline n: Number of cases, SD: Standard deviation, I: Independent samples t-test, C: Chi-square test, \\
NS: Not significant at P $>0.05$, HbA1c: Glycosylated hemoglobin.
\end{tabular}

Comparison of mean OCT and mean vascular access (VA) before and after the intervention in patients who had diabetes mellitus classified according to $\mathrm{HbA} 1 \mathrm{c}(\mathrm{HbA} 1 \mathrm{c} \leq 7 \%$ and $\mathrm{HbA} 1 \mathrm{c}>7 \%)$ is shown in Table 2. Before the intervention, we found no significant difference in mean OCT between study groups ( $p>0.05)$, but after the intervention, there was a reduction in mean $\mathrm{OCT}$, and the reduction was more pronounced in the group of $\mathrm{HbA} 1 \mathrm{c}$ of $<7 \%$ ( $p<0.001)$. About VA, we found no significant difference before the intervention and after the intervention, the changes were comparable between both study groups $(p>0.05)$. 
Table 2: The Comparison of mean OCT and mean VA before and after intervention in patients with diabetes mellitus classified according to $\mathrm{HbA} 1 \mathrm{c}$ into (HbA1c $\leq 7 \%$ and $\mathrm{HbA} 1 \mathrm{c}>7 \%$ )

\begin{tabular}{llll}
\hline Characteristic & $\mathrm{HbA} 1 \mathrm{c} \leq 7 \%, \mathrm{n}=45$ & $\mathrm{HbA} 1 \mathrm{c}>7 \%, \mathrm{n}=66$ & $\mathrm{p}$ \\
\hline OCT Pre & & & \\
$\quad$ Mean \pm SD & $380.33 \pm 49.13$ & $409.68 \pm 51.63$ & 0.092 I \\
$\quad$ Range & $280-480$ & $290-500$ & $\mathrm{NS}$ \\
OCT Post & & & $<0.001$ I \\
$\quad$ Mean \pm SD & $265.33 \pm 19.24$ & $348.41 \pm 73.24$ & $\mathrm{HS}$ \\
$\quad$ Range & $240-306$ & $250-475$ & \\
VA Pre & & $0.88 \pm 0.23$ & 0.067 I \\
$\quad$ Mean \pm SD & $0.74 \pm 0.20$ & $0.48-1.3$ & $\mathrm{NS}$ \\
$\quad$ Range & $0.3-1$ & $0.62 \pm 0.22$ & 0.076 I \\
VA Post & & $0.3-1$ & $\mathrm{NS}$ \\
$\quad$ Mean \pm SD & $0.49 \pm 0.20$ & $0.1-0.78$ & \\
$\quad$ Range & n: Number of cases, SD: Standard deviation, I: Independent samples t-test, NS: Not significant at P >0.05, \\
HS: Highly significant at P $\leq 0.01$, OCT: Optical coherence tomography, VA: Visual acuity. &
\end{tabular}

\section{Discussion}

In the past decade, the anti-VEGF therapy had become the gold standard treatment for patients with (diabetic macular edema), however, poor visual and anatomical outcomes had been noticed in many patients using anti-VEGF therapy. This could be in part due to variable systemic factors, for example., diabetic control, hypertension, and nephropathy, which play an significant role in the initiation and progression of (diabetic retinopathy) as well as its response to therapy [16].

In this study, we examine the role of glycemic control (depending on the level of $\mathrm{HbA} 1 \mathrm{C}$ ) on the response to (intravitreal bevacizumab) injections in those patients who had (diabetic macular edema). In our study, patients with good control of diabetes (in those groups with $\mathrm{HbA} 1 \mathrm{C}$ below 7 ) had an improvement in the logMAR VA of 0.4 after 6 months. On the other hand, those with less optimal control of diabetes show less improvement (about 0.25 logMAR) in their VA. We found no statistically significant difference in the final best-corrected VA in both groups $(p=0.76)$.

Regarding the anatomical changes in the retinal thickness, we had noticed a significant reduction in central retinal thickness (165.5 microns) in the group with $\mathrm{HbA1C}<7$ while in the other group (those with $\mathrm{HbA1C}$ above 7), the reduction was less (about 105.3 microns).

The difference was statistically significant $(p<0.0011)$. This suggests that strict control of glucose level during the period of therapy with intravitreal Avastin injections is essential for good clinical outcome in patients with (diabetic macular edema). Consistent with our results, Ozturek et al. found in retrospective case series composed of 65 eyes that after single intra-vitreal injection of ranibizumab lower $\mathrm{HbA} 1 \mathrm{C}$ level was associated with more reduction in central macular thickness [14].

In a prospective analysis on 95 eyes, Warid et al. had found that poor glycemic control ( $\mathrm{HbA} 1 \mathrm{C}$ above 7) was associated with poor visual outcome and less improvement in the central macular thickness after 3 months of (intravitreal bevacizumab) injections in patients with persistent macular edema [16].
Another retrospective study on 124 patients given bevacizumab for (diabetic macular edema) over 1-year duration had demonstrated that patients with baseline $\mathrm{HbA} 1 \mathrm{C}<7$ had better VA at 1 year in comparison with those with poorly controlled diabetes (HbA1C above 7) but there was no significant difference in the final central macular thickness after 1 year between the two groups [17].

In a similar study, Sharma et al had found patients with $\mathrm{HbA1C}<7$ ( $53 \mathrm{mmol} / \mathrm{L})$ had a significant reduction in central macular thickness in comparison to those with HbA1C above 7 , but both groups showing improvement in VA logmar which was not statistically significant [18].

In this study, we had found a disparity between improvement in the central macular thickness and VA after 6 months of the follow-up as patients had good improvement in the macular edema (in both groups) but the visual outcome not improved significantly, especially in those with $\mathrm{HbA} 1 \mathrm{C}$ above 7.

The disparity between the functional and anatomical outcomes in this study may be related to various factors such as macular ischemia, (chronic macular edema), and others. Evaluation of the macular thickness using OCT had crucial clinical importance but macular thickness is just one of the different variables which affecting (VA) such as macular ischemia, epiretinal membrane, and the chronic nature of the edema.

Despite treatment, macular ischemia had a poor visual outcomes, in this study the information regarding the status of macular perfusion was limited as flourscen angiography was not done in all cases. Chronic macular edema might induce irreversible photoreceptors damage which considers important factor in the discordance between anatomical and visual improvement, i.e., reduction in central macular thickness will not contribute to improvement in visión [19].

There are several limiting factors in this study including sample size was small, duration was short for the follow-up and we assess only the influence of one factor which is the $\mathrm{HbA} 1 \mathrm{c}$ and as it is known that diabetic macular edema is a complex problem and the improvement and deterioration of this condition is affected by several local and systemic factors such as obesity, hypertension, and renal function impairment [20]. In summary, intravitreal injections of bevacizumab result in anatomical (macular thickness) and functional (VA) improvement in patients with (diabetic macular edema).

Glycemic control affecting the outcome of the treatment where strict regulation of glucose level have yield maximum benefit from the given therapy. There is a relationship between macular thickness and visual sharpness but the differences in thickness alone do not clarify the final visual outcomes particularly in patients with bad diabetic control who may endure from (chronic macular edema). 


\section{Conclusion}

Intra-vitreal injections of bevacizumab result in anatomical (macular thickness) and functional (vision) improvement in those patients who had diabetic macular edema and strict glycemic control affecting the outcome of the treatment where strict regulation of glucose level have yield maximum benefit from the given therapy.

\section{References}

1. Diabetic retinopathy. American diabetes association. Diabetes Care. 1998;21(1):157-9.

PMid:9538987

2. Klein R, Klein BE, Moss SE, Cruickshanks KJ. The Wisconsin epidemiologic study of diabetic retinopathy: XVII. The 14-year incidence and progression of diabetic retinopathy and associated risk factors in Type 1 diabetes. Ophthalmology. 1998;105(10):1801-15. https://doi.org/10.1016/ S0161-6420(98)91020-X

PMid:9787347

3. Klein R, Klein BE, Moss SE, Davis MD, DeMets DL. The Wisconsin epidemiologic study of diabetic retinopathy. IV. Diabetic macular edema. Ophthalmology. 1984;91(12):1464-74. https://doi.org/10.1016/s0161-6420(84)34102-1 PMid:6521986

4. Early photocoagulation for diabetic retinopathy. ETDRS report number 9. Early treatment diabetic retinopathy study Research Group. Ophthalmology. 1991;98 Suppl 5:766-85.

PMid:2062512

5. Wilson DJ, Finkelstein D, Quigley HA, Green WR. Macular grid photocoagulation. An experimental study on the primate retina. Arch Ophthalmol. 1988;106(1):100-5. https://doi.org/10.1001/ archopht.1988.01060130106038

PMid:3337683

6. Diabetic Retinopathy Clinical Research Network, Wells JA, Glassman AR, Ayala AR, Jampol LM, Aiello LP, et al. Aflibercept, bevacizumab, or ranibizumab for diabetic macular edema. N Engl J Med. 2015;372(2):1193-203. https://doi.org/10.1056/ nejmoa1414264

PMid:25692915

7. Nguyen QD, Brown DM, Marcus DM, Boyer DS, Patel S, Feiner $\mathrm{L}$, et al. Ranibizumab for diabetic macular edema: Results from 2 phase III randomized trials: RISE and RIDE. Ophthalmology. 2012;119(4):789-801. https://doi.org/10.1016/j. ophtha.2011.12.039

\section{PMid:22330964}

8. Brown DM, Nguyen QD, Marcus DM, Boyer DS, Patel S, Feiner L, et al. Long-term outcomes of ranibizumab therapy for diabetic macular edema: The 36-month results from two phase III trials: RISE and RIDE. Ophthalmology. 2013;120(10):2013-22. https:// doi.org/10.1016/j.ophtha.2013.02.034

PMid:23706949

9. Massin P, Bandello F, Garweg JG, Hansen LL, Harding SP,
Larsen $\mathrm{M}$, et al. Safety and efficacy of ranibizumab in diabetic macular edema (resolve study): A 12-month, randomized, controlled, double-masked, multicenter phase II study. Diabetes Care. 2010;33(11):2399-405. https://doi.org/10.2337/dc10-0493 PMid:20980427

10. Mitchell P, Bandello F, Schmidt-Erfurth U, Lang GE, Massin P, Schlingemann RO, et al. The restore study: Ranibizumab monotherapy or combined with laser versus laser monotherapy for diabetic macular edema. Ophthalmology. 2011;118(4):615-25. https://doi.org/10.1016/j.ophtha.2011.01.031 PMid:21459215

11. Heier JS, Korobelnik JF, Brown DM, Schmidt-Erfurth $U$, Do DV, Midena E, et al. Intravitreal aflibercept for diabetic macular edema: 148-Week results from the VISTA and vivid studies. Ophthalmology. 2016;123(11):2376-85. https://doi. org/10.1016/j.ophtha.2016.07.032 PMid:27651226

12. Arevalo JF, Sanchez JG, Lasave AF, Wu L, Maia M, Bonafonte $\mathrm{S}$, et al. Intravitreal bevacizumab (Avastin(®)) for diabetic retinopathy at 24-months: The 2008 Juan verdaguerplanas lecture. Curr Diabetes Rev. 2010;6(5):313-22. https:// doi.org/10.2174/157339910793360842

PMid:20594160

13. UK Prospective Diabetes Study Group. Tight blood pressure control and risk of macrovascular and microvascular complications in Type 2 diabetes: UKPDS 38. BMJ. 1998;317(7160):703-13.

PMid:9732337

14. Ozturk BT, Kerimoglu H, Adam M, Gunduz K, Okudan S. Glucose regulation influences treatment outcome in ranibizumab treatment for diabetic macular edema. J Diabetes Complications. 2011;25:298-302. https://doi.org/10.1016/j. jdiacomp.2010.09.006 PMid:21075650

15. Matsuda S, Tam T, Singh RP, Kaiser PK, Petkovsek D, Carneiro $\mathrm{G}$, et al. The impact of metabolic parameters on clinical response to VEGF inhibitors for diabetic macular edema. J Diabetes Complications. 2014;28(2):166-70. https:// doi.org/10.1016/j.jdiacomp.2013.11.009

PMid:24374138

16. The relationship of glycemic exposure $(\mathrm{HbA} 1 \mathrm{c})$ to the risk of development and progression of retinopathy in the diabetes control and complications trial. Diabetes. 1995;44(8):968-83. PMid:7622004

17. Warid Al-Laftah FA, Elshafie M, Alhashimi M, Pai A, Farouq M Pretreatment clinical variables associated with the response to intravitreal bevacizumab (Avastin) injection in patients with persistent diabetic macular edema. Saudi J Ophthalmol. 2010;24(4):133-8. https://doi.org/10.1016/j.sjopt.2010.05.001 PMid:23960890

18. $\mathrm{HbA} 1 \mathrm{c}$ as a predictor for response of bevacizumab in diabetic macular oedema. BMJ Open Ophthalmol. 2020;5(1):e000449. https://doi.org/10.1136/bmjophth-2020-000449 PMid:32426522

19. Marashi A. Management of diabetic macular edema: an algorithm for treatment decision-making. Retin Physician 2016;13:52.

20. Chung EJ, Roh MI, Kwon OW, Koh HJ. Effects of macular ischemia on the outcome of intravitreal bevacizumab therapy for diabetic macular edema. Retina. 2008;28(7):957-63. https:// doi.org/10.1097//AE.0b013e3181754209

PMid:18698297 